\title{
Pyometra in the postpartum: a forgotten complication
}

\author{
Rana A. Choudhary ${ }^{1 *}$, Kedar N. Ganla ${ }^{1}$, Kavita N. Desai ${ }^{2}$, Priyanka H. Vora ${ }^{1}$
}

\author{
${ }^{1}$ Department of Reproductive Medicine, Ankoor Fertility Clinic, Mumbai, Maharashtra, India \\ ${ }^{2}$ Consultant, Dadar Imaging and Diagnostic Center, Mumbai, Maharashtra, India
}

Received: 03 May 2019

Revised: 30 May 2019

Accepted: 05 June 2019

\section{*Correspondence: \\ Dr. Rana A. Choudhary, \\ E-mail:dr.ranakhan@gmail.com}

Copyright: (C) the author(s), publisher and licensee Medip Academy. This is an open-access article distributed under the terms of the Creative Commons Attribution Non-Commercial License, which permits unrestricted non-commercial use, distribution, and reproduction in any medium, provided the original work is properly cited.

\begin{abstract}
We report a case of 37 years old women who conceived after in vitro fertilization (IVF). Her antenatal course was uneventful. On delivery there was placenta acreta. She later presented in the postpartum period with pyometra. She was managed with conservative treatment. We believe that the placental bed sutures and the sloughing placenta could have led to sterile pyometra in this patient. This rare but important complication need to be kept in mind specially in high risk women with thin endometrium, h/o IVF, cervical encerclage, and placenta acreta..
\end{abstract}

Keywords: Cervical encerclage, Placenta accreta, Pyometra, Thin endometrium

\section{INTRODUCTION}

Pyometra is collection of pus which distends the uterine cavity. The common causes of pyometra are stenosed cervical os due to uterine and cervical malignancy or previous surgery. ${ }^{1,2}$ Other risk factors include fibroid degeneration, endometrial polyps or carcinoma, puerperal infections, uterine compression sutures (B-Lynch suture), congenital cervical anomalies, forgotten intrauterine devices, genital tuberculosis, radiotherapy, following egg retrieval in IVF etc. ${ }^{3,4}$ Pyometra is a rare occurrence with incidence of $0.01-0.5 \%$ in gynaecological patients. Elderly, postmenopausal women, usually with concurrent medical conditions are at higher risk for this. ${ }^{5-7}$

\section{CASE REPORT}

Our patient was a 37 year old women, G3P0L0A2, known hypertensive for the last 4 years. She underwent in vitro fertilization (IVF) for male factor infertility (severe oligoasthenozoospermia). She had history of two previous miscarriages at 8 weeks and 20 weeks of gestation and one curettage done for the same. Her endometrial lining was always thin during treatment, reaching a maximum of $7.5 \mathrm{~mm}$ on the day of embryo transfer. She conceived in the third cycle of IVF and her antenatal course was uneventful. In view of previous losses, modified Shirodkar's cervical encerclage done at 13-14 weeks. The cervical encerclage stitch was removed at 37 weeks. She delivered by elective cesarean section done for breech presentation, a male child of $2.5 \mathrm{kgs}$.

Intraoperatively placenta acreta was noted with continuous bleeding from the placental bed. Hemostatic sutures taken on placental bed with 1-0 vicryl (polyglactin 910). However some bits of placental tissue was left behind as it was adherent to the placental bed and not bleeding. Figure 1 demonstrates the placental bed hemostatic sutures. The patient had an uneventful recovery and was discharged on the fourth day of delivery.

She came for follow up on day 10 with complains of yellowish discharge per vaginum. The patient was asymptomatic except for greenish yellow discharge from the external os visualized on per speculum examination. 


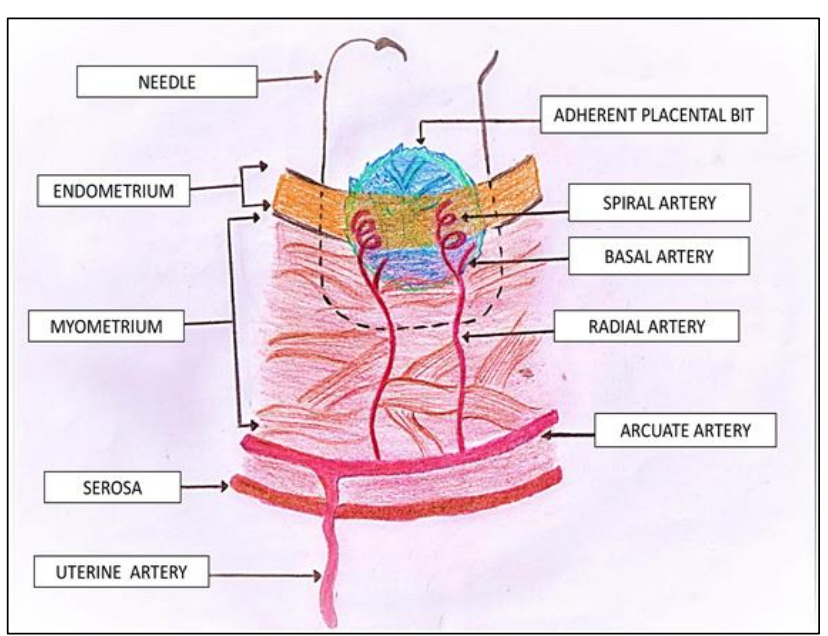

Figure 1: Placental bed hemostatic sutures.

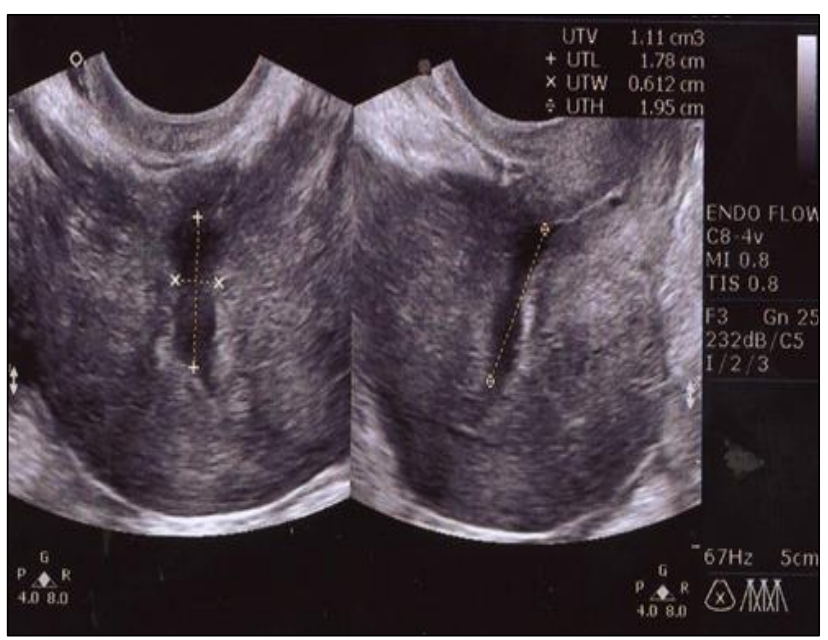

Figure 2: TVS pelvis showing pyometra of uterus.

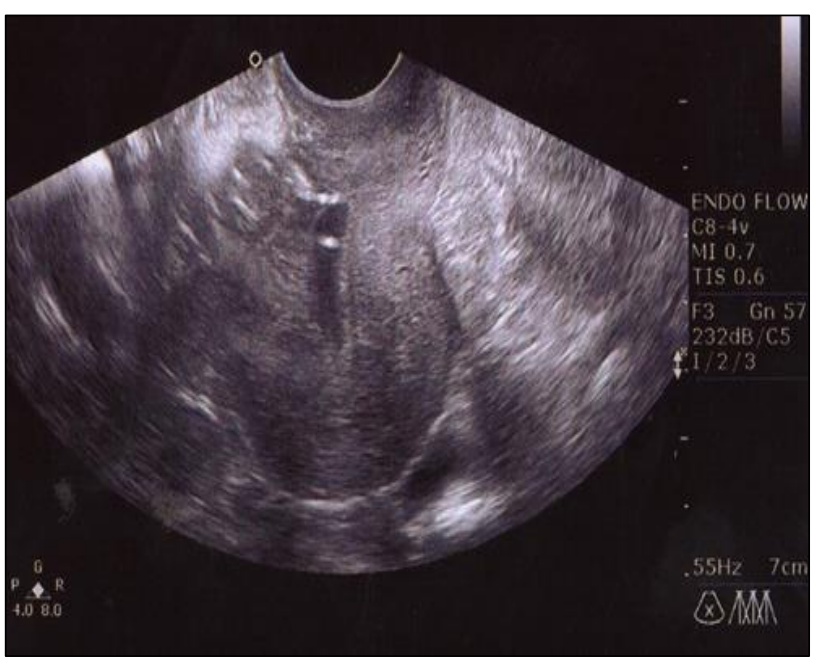

Figure 3: TVS pelvis showing pyometra of uterus with vicryl (polyglactin 910) thread floating in the cavity.

The discharge was collected and sent for culture sensitivity. Meanwhile her complete blood count did not show any leucocytosis. The vaginal discharge report came as sterile pyometra (no organism grown). Ultrasound done on the same day showed a collection in the endometrial cavity ( $\mathrm{vol}=45-50 \mathrm{cc}$ ) which was suggestive of pyometra as seen in Figure 2. Transvaginal ultrasonography of the pelvis showing pyometra of uterus with vicryl (polyglactin 910) thread floating in the cavity as seen in Figure 3.

Since the patient did not have any symptoms or signs of infection, management was a dilemma. The standard management in case of pyometra is drainage of the pus, but in this case the patient was just 10 days post delivery and it was sterile pyometra. After explaining the patient and her husband, trial of conservative therapy was decided. Uterotonic (Tab Methergin) was given thrice a day for 3 days. Her ultrasonography was repeated which showed reduction in the pyometra (Volume of collection $=30 \mathrm{cc}$ ) as seen in Figure 4 .

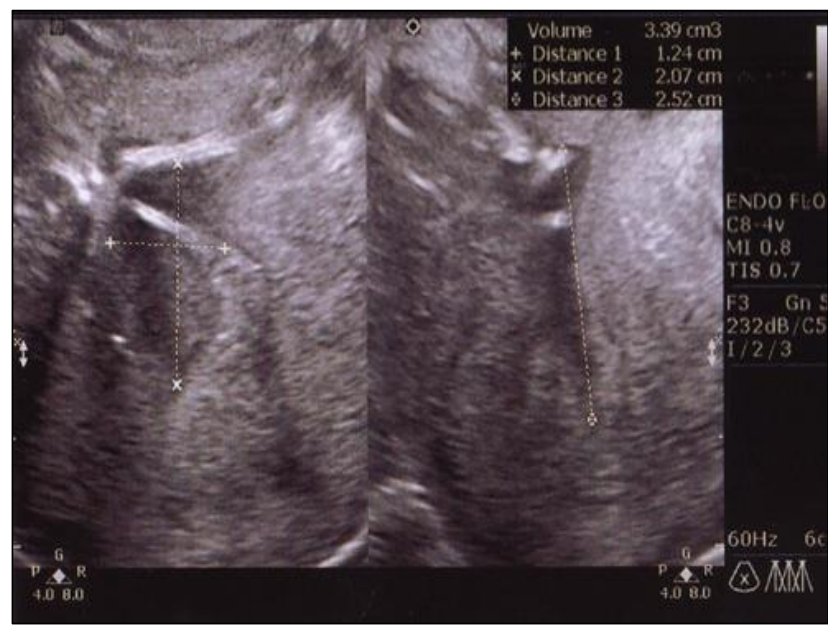

Figure 4: TVS pelvis showing reduction in pyometra of uterus.

The patient did not have any symptoms suggestive of infection and her repeat complete blood count was normal. ${ }^{8}$ Tab methergin was continued for 5 Days and the sonography was repeated after 10 days which showed further reduction in the volume of the pyometra. After two weeks, the uterine cavity did not show any collection and the patient was also asymptomatic.

Thus we were able to manage a case of postpartum pyometra without any surgical intervention.

\section{DISCUSSION}

The placental bed sutures and sloughing placenta added with some amount of cervical stenosis (due to cervical encercalge) could have led to sterile pyometra in this patient. It is a rare but important complication, specially in high risk women. Table 1 enumerates the high risk factors for developing pyometra. 
Table 1: : High risk factors for developing pyometra.

\begin{tabular}{|l|}
\hline Risk factors for developing pyometra \\
\hline Pre conception- Thin endometrium \\
\hline H/o IVF /ICSI conception \\
\hline Placenta acreta \\
\hline Cervical encerclage leading to cervical stenosis \\
\hline Hypertension \\
\hline
\end{tabular}

Literature review did not show any case report of post partum pyometra. Early diagnosis is extremely important in pyometra as the sterile pus may get infected and lead to serious complications such as puerperal sepsis, spontaneous perforation as reported in a case series in 27 women. ${ }^{6}$ Hypoalbuminaemia is an important predisposing factor for perforation. The prognosis depends upon the underlying cause (e.g. malignancy) and whether there was a spontaneous perforation or not. ${ }^{9,10}$

A retrospective study conducted over a period of 8 years in which the incidence of pyometra was $0.038 \%$ of all gynecologic admissions. ${ }^{6}$ Some of the common risk factors for the same were $(22.2 \%)$ associated malignancy, (3.7\%) genital tract abnormality, $(74.1 \%)$ idiopathic in elderly \& concurrent medical conditions. ${ }^{6}$ Of these $18.5 \%$ had spontaneous perforation of pyometra, 33.3\% had persistent / recurrent pyometra and only $1 \%$ were asymptomatic. ${ }^{6}$

The common symptoms in these women are bloodstained purulent vaginal discharge, symmetrical uterine enlargement, lower abdominal pain, pyrexia (rare) and extremely rare spontaneously perforation and acute abdomen. ${ }^{9}$ Differential diagnosis can become challenging many times with some of the differentials being fibroids, adenomyosis, endometrial polyps, cancer, haematometra \& gestational trophoblastic neoplasia. Differentials in patients presenting with blood-stained vaginal discharge could be vaginosis, vulvar vestibulitis and genital infections or puerperal sepsis. ${ }^{10,11}$ Investigations in these cases are by microbiology of the discharge. However, the vaginal swabs may be negative in up to $50 \%$ of cases as anaerobes are difficult to culture. In cases where tuberculosis is suspected, a BACTEC culture, histology and PCR may be required. Other imaging modalities like ultrasound, plain X-ray / CT scan in pneumoperitoneum and CT and MRIfor suspected perforated pyometra are also used. Doppler scanning will help to assess the blood flow changes particularly in cases of endometrial cancer. Management options include regular monitoring of the vitals of the patient and the volume of pyometra. Cervical dilation and drainage of collection is the standard method of treatment. However, antibiotics are only necessary if there is evidence of invasive infection like generalized malaise, pyrexia, or altered laboratory parameters. If antibiotics are used, they should be broad spectrum to cover aerobic as well as anaerobic bacteria. In cases of tubercular pyometra, AKT is required. Hysterectomy may be the treatment of choice in malignancies. ${ }^{12}$

Pyometra in the postpartum period is an extremely rare condition. Hence we have to be more vigilant especially in high risk women with adherent placenta, history of IVF, thin endometrium, cervical stenosis, cervical encerclage, hemostatic compression sutures (B lynch etc). Early diagnosis and management will prevent future grave complications like puerperal sepsis, perforation and acute abdomen and hence prevent maternal morbidity and mortality.

\section{Funding: No funding sources \\ Conflict of interest: None declared \\ Ethical approval: Not required}

\section{REFERENCES}

1. Toglia MR, Fagan MJ. Pyometra complicating a LeFort colpocleisis. Int Urogynecol J Pelvic Floor Dysfunct. 2009;20(3):361-2.

2. Schlumbrecht M, Balgobin S. Pyometra after thermal endometrial ablation. Obstet Gynecol. 2007;110(2 Pt 2):538-40.

3. Yildizhan B, Uyar E. Spontaneous perforation of pyometra. Infect Dis Obstet Gynecol. 2006:267-86.

4. Hofmann GE, Warikoo P. Ultrasound detection of pyometra at the time of embryo transfer after ovum retrieval for IVF. Fertil Steril. 2003;80(3):637-8.

5. Yildizhan B, Uyar E. Spontaneous perforation of pyometra. Infect Dis Obstet Gynecol. 2006;2006:26786.

6. Chan LY, Lau TK. Pyometra. What is its clinical significance? J Reprod Med. 2001;46(11):952-6.

7. Barry C. Pyometra in childhood. Obstet Gynecol. 2015;125(5):1035-8.

8. Rebecca Allen. Uses of Methergin in Obstetrics and Gynecology. Rev Obstet Gynecol. 2017;2(3):159168.

9. Chan LY, Yu VS. Spontaneous uterine perforation of pyometra. A report of 3 cases. J Reprod Med. 2000;45(10):857-60.

10. Ou YC, Lan KC. Clinical characteristics of perforated pyometra and impending perforation: specific issues in gynecological emergency. J Obstet Gynaecol Res. 2010;36(3):661-6.

11. Sirha R, Miskin A, Abdelmagied A. Postnatal pyomyoma: a diagnostic dilemma. Case Reports 2013; bcr2013201137.

12. Shayya RF. Pyometra after Le Fort colpocleisis resolved with interventional radiology drainage. Obstet Gynecol. 2009;113(2 Pt 2):566-8.

Cite this article as: Choudhary RA, Ganla K, Desai K, Vora P. Pyometra in the postpartum: a forgotten complication. Int J Reprod Contracept Obstet Gynecol 2019;8:2923-5. 